\title{
A Pre-exploration Technique for Mapping Petroleum Potential Areas Based on Induced Surface Alterations and Possible Traps
}

\author{
Chrisphine Ouko, Felix Mutua*, Mercy Mwaniki \\ College of Engineering, Jomo Kenyatta University of Agriculture and Technology, Nairobi, Kenya
}

Copyright $\bigcirc 2018$ by authors, all rights reserved. Authors agree that this article remains permanently open access under the terms of the Creative Commons Attribution License 4.0 International License

\begin{abstract}
The process of determining hydrocarbon potential areas for exploration requires numerous extensive studies of both surface and subsurface structures. Analysis and good understanding of these structures and surface expressions related to hydrocarbon formation provides a basis for identifying petroleum traps. The existence of favorable subsurface conditions for petroleum accumulation is always dependent on surface manifestation of petroleum traps. Identifying these areas prior to exploration allows for proper planning of seismic works so as to focus exploration and resources on relatively small areas. The main objective of this study was to locate and map petroleum potential areas in parts of Turkana by integrating spatial data derived from geology, gravity and remote sensing. Six predictor maps were developed including; alteration, lineament density, residual gravity anomaly, proximity to fault, lithology and regional gravity anomaly. The maps were analyzed using Artificial Neural Network (ANN) model to generate petroleum potential map. The map was further classified to high, moderate and low potential zones. The final petroleum potential map was validated by 9 existing wells that were not used in training. The final map demarcated an area of $8,994.41 \mathrm{Km}^{2}$ equivalent to $55.9 \%$ of the total study area as high potential.
\end{abstract}

Keywords ASTER, Alteration, Gravity, Artificial Neural Network, Lithology, Lineaments, and Hydrocarbon

\section{Introduction}

The process of carrying out petroleum exploration involves a series of studies and procedures that require scientific understanding of the existing geological formation and their distribution within a given area. The surface features such as rocks and structures together with the underlying rock formation may provide a hint on presence of petroleum. Currently, remote sensing techniques are considered as very useful tool for evaluating basins for hydrocarbon. Both satellite and airborne sensors have always provided useful information especially when integrated with other exploration techniques such as gravity, magnetic, seismic and well data [1].

Hydrocarbon potential mapping is a Multi-Criteria Decision Making (MCDM) technique which generate predictive model for delineating favorable areas within a given study area. Several approaches exist and can be categorized into data-driven and knowledge driven [2]. In knowledge driven, occurrences are estimated based on expert opinion and include methods such as weighted index overlay [3], fuzzy logic [4], [5] and Multi-Criteria Evaluation (MCE) [6]. In the other technique called data driven or empirical, model parameters are estimated from measured data [2]. The known mineral deposits or wells in a given area are used as 'training points' to create a spatial relationship between known occurrences and particular geologic, geochemical and geophysical features [7], [8]. Examples of data-driven techniques and applications include regression [9], weights of evidence [10] and artificial neural networks (ANN) [11]. Other techniques aimed at integrating data in a GIS environment to identify favorable areas have also been applied. A number of studies on these other techniques have been carried out by different researchers including [12], [13] and [14], [15].

In this study, different predictors were used as inputs for MCDM technique based on Probabilistic Neural Network (PNN) in Artificial Neural Network (ANN). The technique is applied to gravity (residual and regional), remote sensing (alterations and lineament), geology (fault), lithology and well data.

\subsection{Remote Sensing Techniques}

Every material on the earth surface exhibits a unique reflection and emittance behavior that can be used to 
classify them from either space or air. Based on their reflectance and emittance behavior, surface materials containing hydrocarbon can be detected directly through satellite image processing techniques focused on spectral characteristics of the hydrocarbon. Each of these techniques are based upon the conditions of surface alteration of soils, minerals and stress on vegetation [16]. [17] Reported that, seeping hydrocarbon can affect the $\mathrm{pH}$ of the surrounding geology causing mineral alteration effects such as loss of oxy-hydroxides (hematite and goethite) and formation of ferrous-bearing minerals (e.g., magnetite and pyrite), clays (e.g. Illite and kaolinite) and carbonates (e.g., dolomite and calcite). Mineral alterations associated with hydrocarbon seepage have been investigated by numerous authors including [18], [19], [20] among others due to their potential in petroleum exploration.

The application of remote sensing in hydrocarbon and mineral mapping are based on the sensor capability to register spectral signatures and other geological features related to mineral deposits [21]. [19] Stated that, the key to successful application of remote sensing lies in its integration with other exploration tools such as seismic, well, gravity and magnetic data.

The Advanced Space-borne Thermal Emission and Reflection Radiometer (ASTER) multispectral sensor launched in December 1999 records solar radiation in 14 spectral bands across three wavelength regions, that is Visible Near Infrared (VNIR), Short Wave Infrared (SWIR) and Thermal Infrared Radiation (TIR) which are very sensitive to a range of geologically important minerals [18]. The first three bands are at a spatial resolution of $15 \mathrm{~m}$ and measures radiation from 0.52 to $0.86 \mu \mathrm{m}$ in VNIR; the next six bands measures radiation from 1.6 to $2.43 \mu \mathrm{m}$ at $30 \mathrm{~m}$ spatial resolution in SWIR; the last five bands are thermal and measures radiation from $8.125-11.65 \mu \mathrm{m}$ at $90 \mathrm{~m}$ spatial resolution [22]. ASTER data and other satellite remote sensing data have been successfully used for alteration mapping for minerals to aid in exploration by [23], [8], [24], [25], [26], [21].

\subsection{Modelling Parameters}

The iron bearing minerals (e.g., magnetite and pyrite), carbonates (e.g., dolomite and calcite), hydrates and hydroxide minerals such as gypsum and clays (e.g., illite and kaolinite) always display molecular absorption features that are related to their overtones and combination tones in the Visible Near Infrared (VNIR) and Short-Wave Infrared (SWIR) [27]. These changes are some of the most common alterations related to minerals induced by hydrocarbon seepage according to [17]. Hydrocarbon induced alteration and its application in mineral and petroleum exploration have been reported by researches in various areas including: [20]; [28]; [29]; [13]; [16]; [30]; [26]. These studies have demonstrated the effectiveness of induced alterations derived from satellite images in both minerals and petroleum mapping.

Lineaments data provides important information on subsurface fracture and cracks which can be analyzed to identify the structural style, trapping mechanism and correlation analysis of surface linear features and subsurface oil and gas traps. Study of surface lineaments for analysis of lithology, petroleum and mineral exploration has been employed by many researchers including [6], [9], [31], [32], [33], [14].

Gravity data due to their ability to model subsurface geology and predict possible areas of favorable hydrocarbon accumulation within a basin, have been applied in hydrocarbon exploration. A good understanding of basin framework a long with structural and tectonic features relating to basin sedimentation always leads to successful hydrocarbon exploration in undrilled portions of a basin. Low density volcanic and sediment accumulation are very significant in hydrocarbon accumulation due to their richness in organic matters. Analysis of gravity data in petroleum exploration have been reported by many researches including; [6], [3], [1], [34], [35], [36], [31].

Lithology and surface structure are considered important in petroleum exploration due to their ability to provide a basis of understanding the geological setting of an area in relation to hydrocarbon controlling parameters. Application of lithology in mineral exploration has been carried out by the following researchers; [5], [8], [15], [9].

Faults mapping is always important in petroleum exploration since most oil and gas fields are always aligned along major fault trends. Faults, joints and cracks normally act as main pathways for leaking hydrocarbon to the surface. When basement faults systems are propagated upward towards the surface, they may provide a mechanism for migration and entrapment of hydrocarbon [37].

\subsection{Artificial Neural Network (ANN)}

Artificial neural network (ANN) is a multipurpose and universal predictor that is capable of forecasting occurrence with high degree of accuracy [38]. There are various types of ANNs which differ from each other based on the number of neurons, neuron interconnection, activation type and learning algorithm. They include multi-layer perception [39], the radial basis function link network ([30], [11]), Recurrent Neural Network (RNN), adaptive resonance theory network [39], and probabilistic neural network (PNN) [40], [41], [42] and [43]

In this study, PNN is used to predict potential petroleum areas. The PNN was chosen because of its ability to train at high speed and also for being able to produce high confidence levels for classification decisions, unlike other neural networks training paradigms. The main goal of PNN is to make an estimate of the probability that an unknown mineral deposit belongs to a given deposit type. Some of 
the distinguishing features that make PNN valuable for prediction includes: PNN require no assumptions about distributions of random variables used for classification; they are able to handle multimodal distributions; they have the ability to provide mathematically sound confidence levels; and they are relatively insensitive to outliers [44].

The PNN architecture is made up of many interconnected processing units or neurons organized in successive layers. The input layer unit does not perform any computation and simply distributes the input to the neurons in the pattern layer.

\section{Study Area and Geological Setting}

\subsection{Study Area}

In this research, a section of Turkana county located in north-western Kenya and covering mainly block 10BB and $13 \mathrm{~T}$ was selected for analysis and mapping of petroleum potential areas. The study area as shown in Figure 1 by area of interest (AoI) is the current subject of crude oil exploration in Kenya. In geographical context, the study area lies between latitudes ( $1^{\circ} 45^{\prime} 52.86^{\prime \prime} \mathrm{N}$ and $2^{\circ} 59^{\prime}$ $\left.28.63^{\prime \prime} \mathrm{N}\right)$ and longitudes ( $34^{\circ} 55^{\prime} 46.95^{\prime \prime} \mathrm{E}$ and $36^{\circ} 32^{\prime}$ 10.58" E) and covers an area of approximately 16,079.51 $\mathrm{km}^{2}$. The study area is also crossed by two rivers namely river Turkwel and Kerio.

\subsection{Geological Setting}

In geological context, the study area partly covers Lokichar and Kerio basin, which are part of sedimentary rift-basin in northwest Kenya. The basins attracted potential petroliferous sedimentary piles $(\sim 2000-5000 \mathrm{~m}$ thick) which were deposited on basement rocks of Precambrian age and later got covered by basaltic flows of mainly Miocene age. Sedimentation in these intra-cratonic rift basins was controlled by intra-basinal and marginal faults, some of them reaching also the basement [45] and [34]. Lokichar basin is segmented as N-S-trending tertiary Kenya rift belonging to the Great East African Rift system caused by E-W extensional rift tectonics [46]. The fill of the basin is $7 \mathrm{~km}$ thick. Kerio basin is a typical half-graben, more than $8 \mathrm{~km}$ deep, the basin is filled by alternating fluvial and lacustrine sediments and thick piles of volcanic.

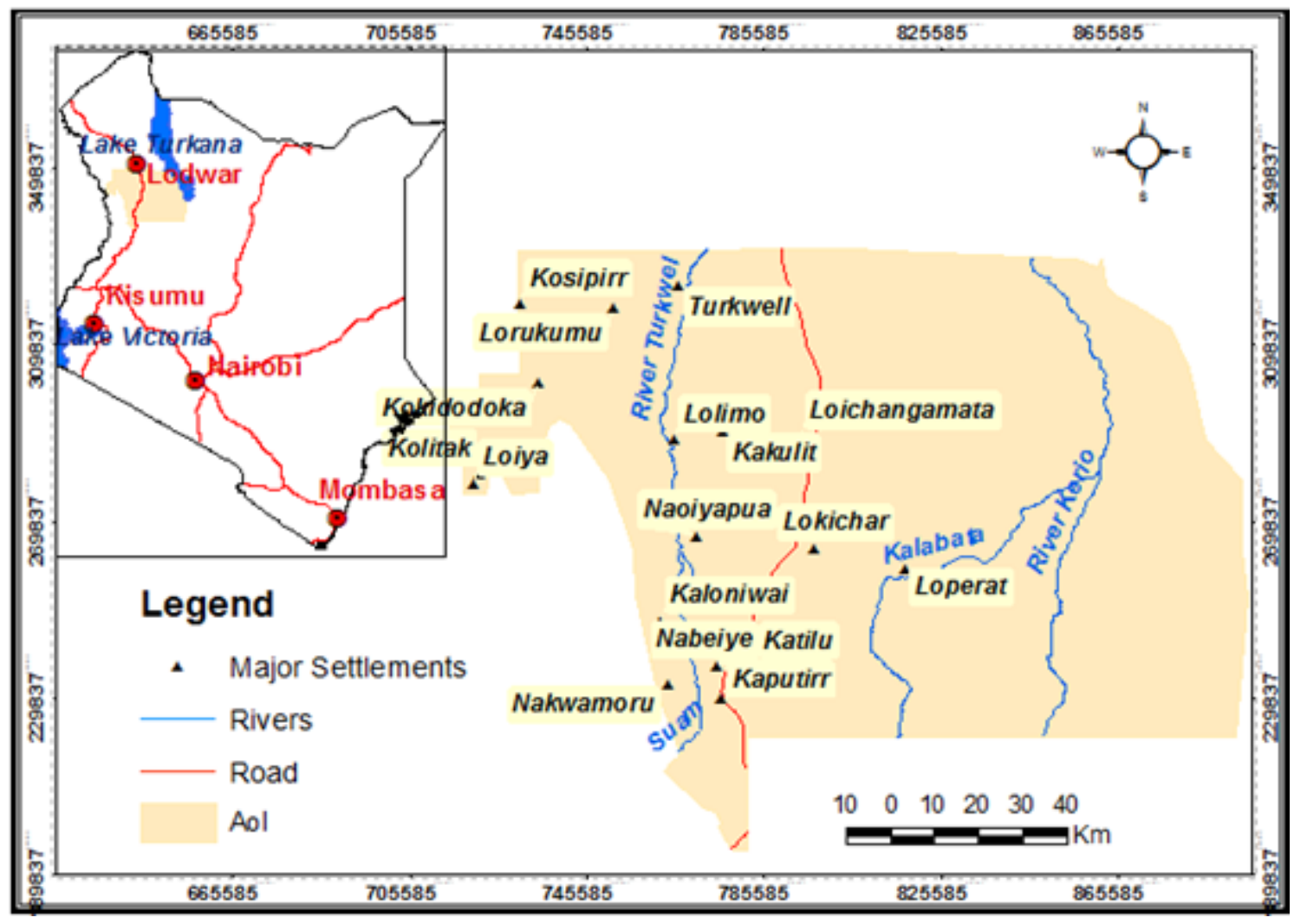

Figure 1. A representative map of study area 


\section{Materials and Methods}

\subsection{Materials (Data Used)}

In order to locate the potential zones for exploration, different predictor maps used as proxies were prepared from gravity data (residual and regional gravity map), geological data (proximity to fault map), lithology data (lithology map) and satellite remote sensing data (alteration and lineament density map).

\subsubsection{Satellite Remote Sensing Data}

A cloud free ASTER image in Level 1-T acquired between 2003 and 2004 was obtained from USGS Earth explorer website for the study area and used to map alterations and lineaments. Alterations and lineaments were then derived based on the nine pre-processed bands.

\subsubsection{Gravity Data}

Scanned Gravity data was obtained from National Oil Corporation of Kenya (NOCK). The data was based on catalogue of gravity measurements in Kenya collected between the year 1955 and 1975.

\subsubsection{Geological Data}

Five scanned Geological maps at a scale of 1:125,000 were obtained from Geological Survey of Kenya. The scanned geological maps were used to generate fault map.

\subsubsection{Lithology Data}

The lithology data was obtained from International
Livestock Research Institute (ILRI) website.

\subsection{Study Methodology}

Figure 2 below demonstrate the procedure followed to generate the final petroleum potential map.

In the first step, data is extracted from various sources and georeferenced. Each extracted data is analyzed independently to identify their contribution to hydrocarbon existence inform of predictor maps. All predictor maps are then converted to raster for modelling in ANN using well data as training file.

\subsubsection{Remote Sensing Data Analysis Technique}

The main objective of remote sensing data analysis was successful identification of altered minerals and classification of lineament density map using ASTER data. Since ASTER data was obtained at different dates, the pre-processing technique was carried out on each scene separately. Both 15m VNIR and 30m SWIR bands were corrected for atmospheric effects on surface reflectance for each band based on FLAASH atmospheric model and converted to radiance at the sensor using sensor radiometric coefficients. The $15 \mathrm{~m}$ resolution atmospherically corrected VNIR ASTER data was resampled to correspond to $30 \mathrm{~m}$ SWIR band using nearest neighbour resampling technique. The three VNIR bands were then combined with six SWIR bands to produce a nine band ASTER image. The nine-band image data was also georeferenced to UTM zone $36 \mathrm{~N}$ based on the geographic location of the study area. Image processing techniques for both induced alteration and lineaments were then carried out separately.

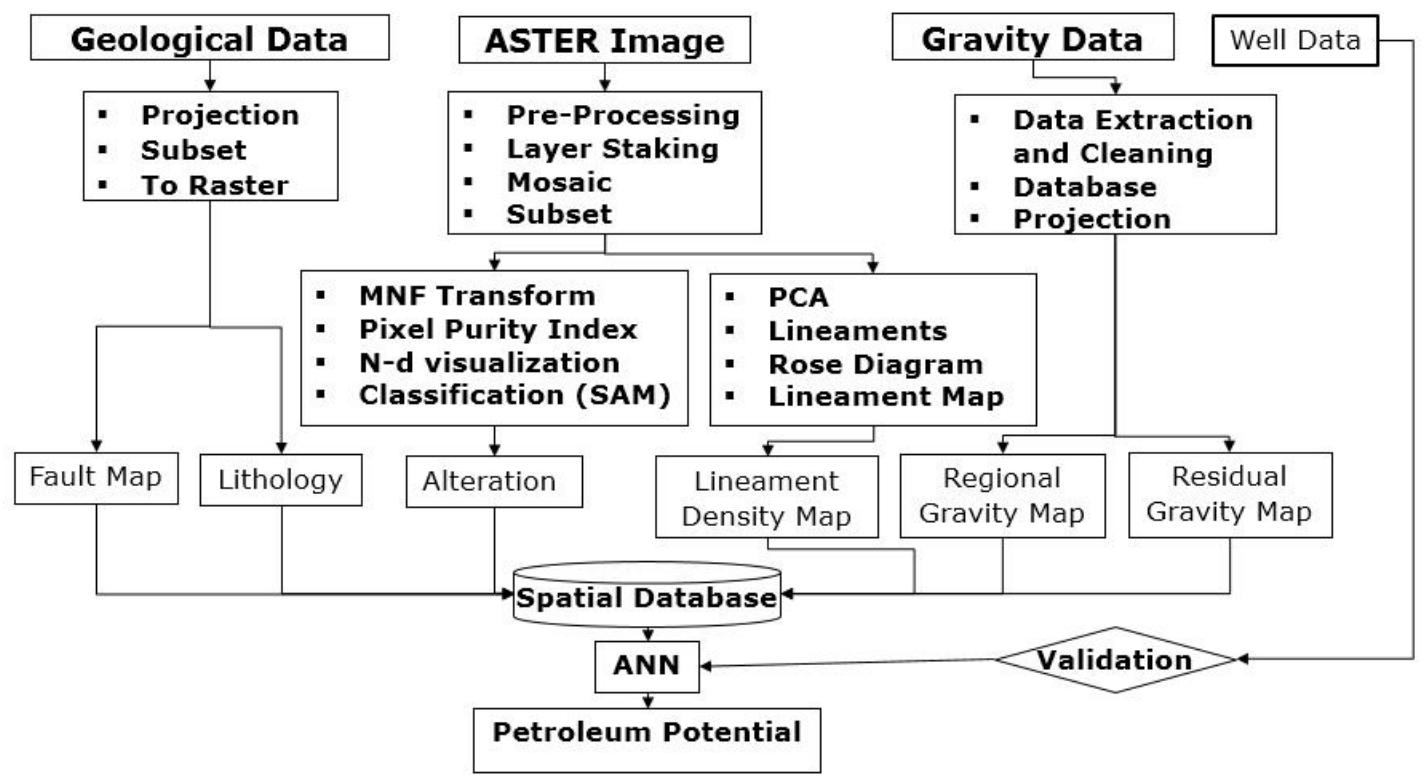

Figure 2. Flow chart methodology describing data processing steps 
Alteration: Supervised classification based on spectral characteristics of each end-member was conducted. To achieve this, spectral characteristics for both altered and unaltered areas were first investigated to identify end-members belonging to each specific mineral from the image and later compare them with USGS spectral reflectance from the library.

Four image processing steps were carried out using Environment for Visualising Image (ENVI) based on spectral hour glass. First step in modelling the pre-processed ASTER image was to perform Minimum Noise Fraction (MNF) so as to determine inherent image data dimensionality to segregate and equalize the noise in the data. In order to identify the most spectrally pure pixels from the MNF image, Pixel Purity Index (PPI) was computed. Spectra of diagnostic hydrocarbon alteration minerals were extracted as end-members from the pure pixels of the image using n-dimensional visualizer tool by selecting extremely located pixels within the visualizer. With supervised digital image classification based on Spectral Angle Mapper (SAM) technique, the identified end-members were assigned to classes according to similarity between the spectral signature of each image pixel and the spectral signature of end-member in the USGS spectral library. Five end-members were identified, including a-alunite, dolomite, magnetite, alunite and kaolinite. In order to determine the contribution of the identified altered areas to hydrocarbon accumulation, the identified end-members were converted to vectors and stored as shapefile.

Lineaments: Image enhancement techniques such as contrast stretching and directional filtering were used to extract lineaments. 3 by 3-pixel box kernel was applied in ENVI to filter the pre-processed image for lineament extraction. Filtered images in E-W, N-S, NW-SE, and NE-SW directions were generated and used as input images in PCI Geomatica for automatic lineament extraction. The algorithm for lineament extraction in Geomatica software consist of edge detection, thresholding and linear extraction steps which were carried out.

Structural lineaments were carefully interpreted, excluding man-made lineament networks such as roads, footpaths, drainage and ditches. The extracted lineaments were converted to shapefile and taken to ArcMap for further processing analysis. Line splitting for lineaments with more than two nodes and lineament density was done in ArcMap. Lineaments frequency and their rose diagrams were prepared and analyzed in Rock Works software to examine their trends in the study area.

\subsubsection{Gravity Data Processing}

Microsoft office excel was used to extract the gravity data from the scanned data for each gravity station. Since latitude, free air, bouguer, topographical and tidal corrections had been applied to the measured gravity data in order to obtain Complete Bouguer Anomaly (CBA) data, no any other correction was carried out to the data. The location coordinates were re-projected to UTM zone $36 \mathrm{~N}$. The CBA data together with the location coordinates were first entered in Microsoft excel for each station point. Processing of the data was then done using Oasis Montaj software.

In order to obtain the residual and regional gravity anomaly maps, the following steps were carried out. First, CBA data was gridded using minimum curvature algorithm to generate a smooth grid. Interactive filtering was then performed using Forward (FFT) Fast Fourier Transform to convert the gridded image data into a frequency domain image that displays the spatial frequency components in all direction. Radially averaged power spectrum and depth estimation for density interfaces of the Forward (FFT) image was then calculated to show densities contributing to long and short wavelengths and plotted. Using Gaussian Regional/Residual filter, regional and residual gravity anomaly maps were generated. Both residual and regional gravity data were exported as GeoTIFF to ArcMap. Using raster properties in data management tools, a color map was created for each anomaly.

\subsubsection{Lithology}

Lithology map of Kenya obtained from ILRI was used to identify the various lithologies in the study area. The map was clipped to AoI then converted to raster for model input.

\subsubsection{Proximity to Fault}

Identification of fault in the study area was done by on-screen digitization from scanned georeferenced geological maps at a scale of 1:125,000. Final fault map was generated. Fault map was then rasterized using feature proximity tool in spatial data modeler (SDM) tool at an interval of $5 \mathrm{~km}$ to produce proximity to fault map.

\subsection{Modelling Approach}

The choice of input parameters that guides in determining petroleum potential areas was carried out based on the available data for the study area and by considering their contribution to hydrocarbon existence. The study methodology adopted was based on a major strength of GIS, the ability to integrate and combine multiple layers of geo-science data into mineral prospectivity maps showing areas that are favourable for mineral exploration [47].

\subsubsection{Artificial Neural Network Model Construction}

In this study, a multilayer perceptron (MLP) feed-forward network was used [39] as shown in Figure 3 below. The first step in building the model was to define the data as input in neural network so as to generate the classification and training data to be used in GeoXplorer for modelling. The training data was created from the existing well location data in the study area, non-well 
location and unique condition raster obtained by combining all input raster's (predictor maps). A total of 20 known wells locations were added to the study. 20 non-wells selected based on posterior probability derived from weight of evidence of the input predictor layers were also added to represent non-training sites (areas considered not to contain petroleum). The reason for this selection was to allow for inclusion of both positive (wells) and negative (non-wells) so as to reflect to some extent the probability distribution of occurrences in the study area. The selection of equal number of both training and non-training sites is to allow the model to perform efficient classification based on the input predictor maps. This is significant in optimizing network performance during both training and classification phase [40].

The wells and non-wells data were tuned into fuzzy based on "large" and "small" pertinence functions and number kept equal respectively. Thus, well locations representing petroleum areas were coded a value of 1 and non-well a value of 0 . The input variables were combined to one unique condition raster and each linearly rescaled to the range of $[0,1]$.

\subsubsection{Model Implementation}

Three steps including: model and architecture selection; training; and performance assessment are always considered necessary for ANN network implementation [48]. The input predictors were set to 6 and output layer set to 1 . The architecture selection involves choosing the number of hidden layers by the model.

Training of neural network for multi-source classification require two stages; training stage whereby the internal weights are adjusted and the classification stage where the probability of occurrence is computed. GeoXplorer was used to perform the training and classification based on PNN modelling technique. The training stage was done using the train-file generated from neural network input file in ArcMap with the proportion value for thinning the training vectors set to 0.2 . Classification was carried out after training stage based on the class-file, also generated from ANN input file in ArcMap. By running neural network output file for PNN using the PNN classification file from GeoXplorer, probability of petroleum occurrence was generated.

In order to assess the performance of the PNN model in predicting the potential areas, an independent performance was done by presenting the network with previously withheld test. 9 known well sites and 9 non-well sites that were not used in modelling were selected to represent the validation points. This was equivalent to 0.310 or $31 \%$ of the total number of training points used in the study. A common procedure during evaluation of a trained ANN is to use one-third of the training points for validation [40]. This ensured that the model will not only fit the training data, but also previously unseen data, which is always essential in predictive mapping. The distribution of these validation points was based on the available well and non-well sites in the study area.

A petroleum potential map was finally generated based on the predictor maps and training data for wells and non-wells.

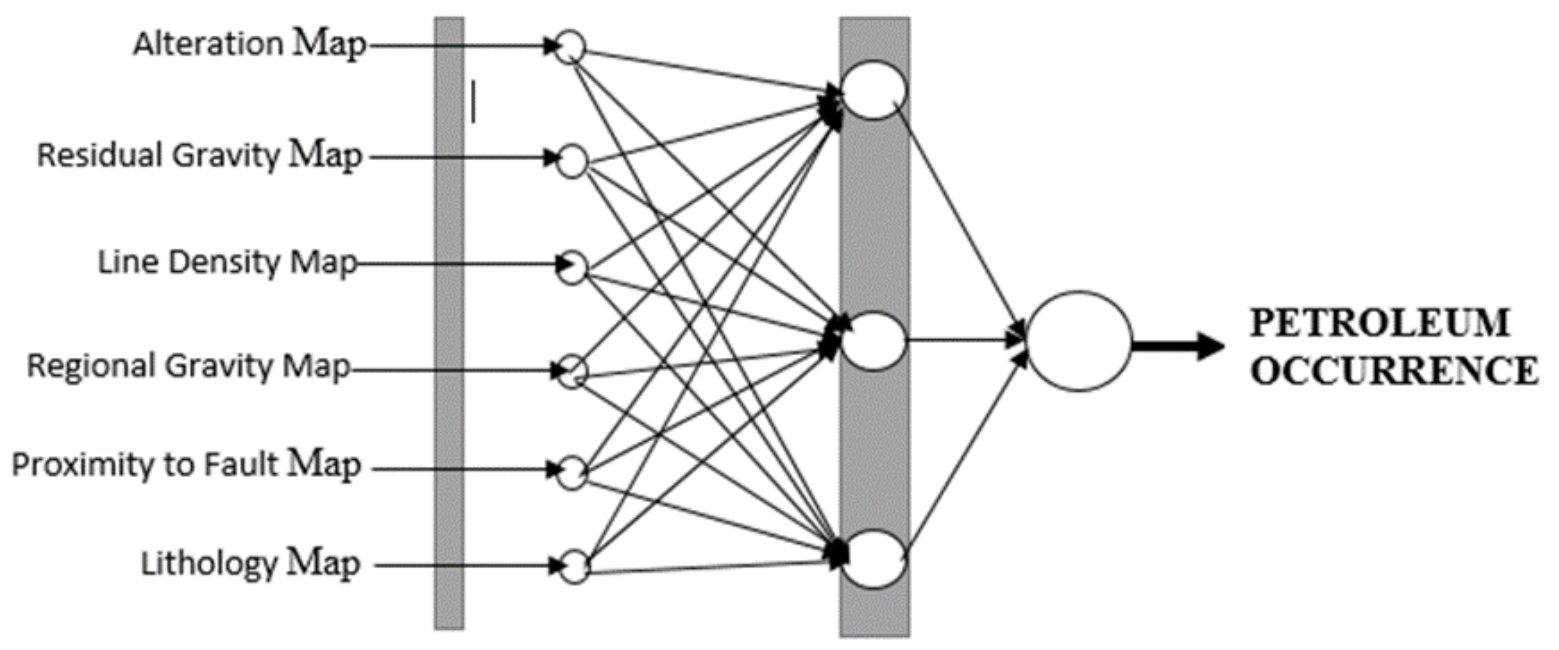

Input Layer

Hidden Layer

Output Layer

Figure 3. Structure for network model used for petroleum potential mapping 


\section{Study Results}

\subsection{Predictor Maps}

The predictor maps generated in this study are very essential in modelling hydrocarbon migration and accumulation. Each predictor offers a unique indication of hydrocarbon potential based on parameters controlling hydrocarbon formation and existence.

\subsubsection{Alteration Map}

Alteration mineral associated with petroleum were successfully identified and mapped using SAM classification technique as shown in Figure 4. The alterations mapped includes; kaolinite, magnetite, dolomite, illite, ammonia alunite (a-alunite) and alunite. All the five minerals were extracted in reference to USGS spectral library. Overall, the spectra of field samples and the USGS spectral library do have different reflectance level, but similar reflectance curves.

ASTER image spectra for the derived minerals compared with the laboratory spectra of each alteration are shown in (Figure 5). A comparison of all the derived alteration minerals with corresponding image spectra from USGS spectral library was generated to demonstrate the reflectance pattern of each mineral. Based on the reflectance curves, similar patterns were registered as shown in Figure 5 (A to F). The total reflectance of magnetite is always low as shown. Presence of magnetite is as a result of migrating hydrocarbon causing reduction of hematite to form magnetite. Kaolinite, alunite and a-alunite are typical constituents of argillic alteration which exhibits intense Al-OH absorption near $2.17 \mu \mathrm{m}, 2.15 \mu \mathrm{m}$ and 2.1 $\mu \mathrm{m}$ respectively. A reducing environment created as a result of slight acid condition could have promoted weathering of feldspars to produce clay and further conversion of illite clay to kaolinite. Dolomite exhibits $\mathrm{CO}_{3}$ absorption features near $2.30 \mu \mathrm{m}$ and focuses on 0.52 to $2.43 \mu \mathrm{m}$ wavelength region for both VNIR and SWIR. Presence of dolomite confirmed the existence of diagenetic carbonates that normally acts as indicator for hydrocarbon induced mineralization.

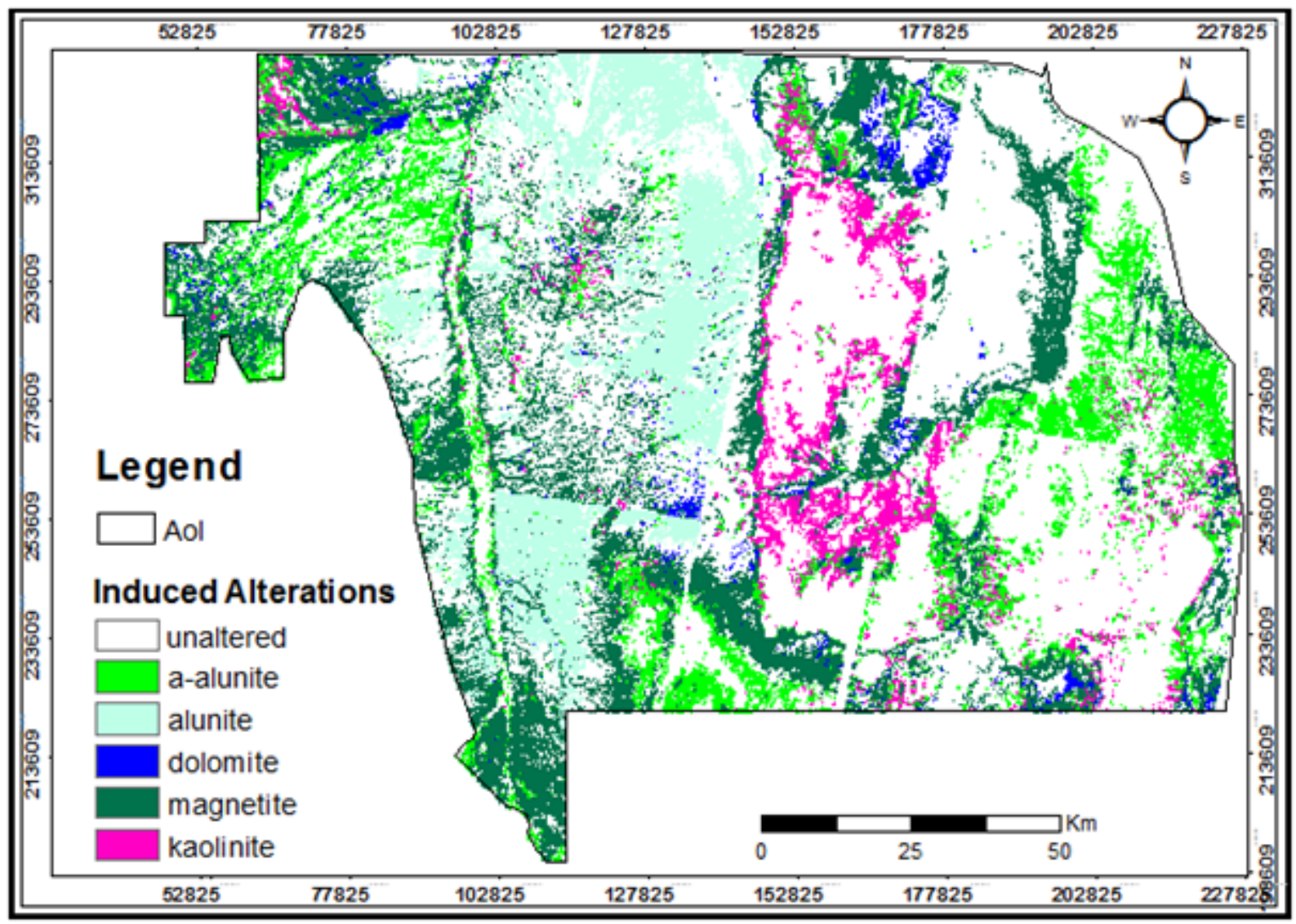

Figure 4. Map showing distribution of alterations within the study area 

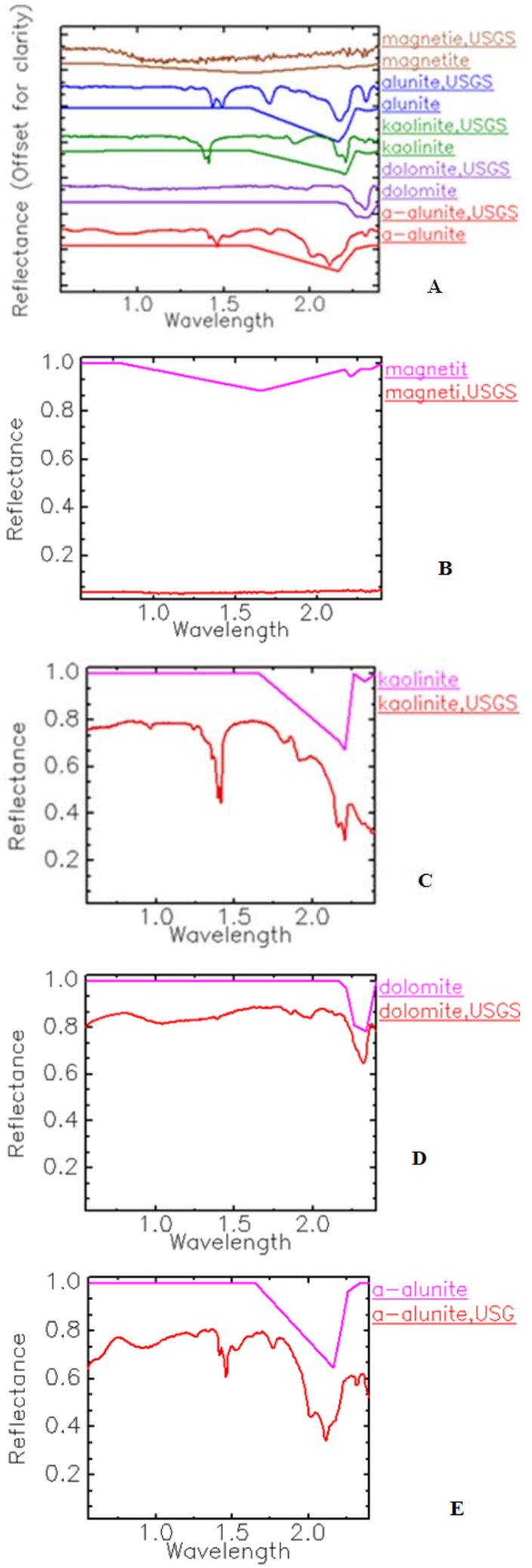

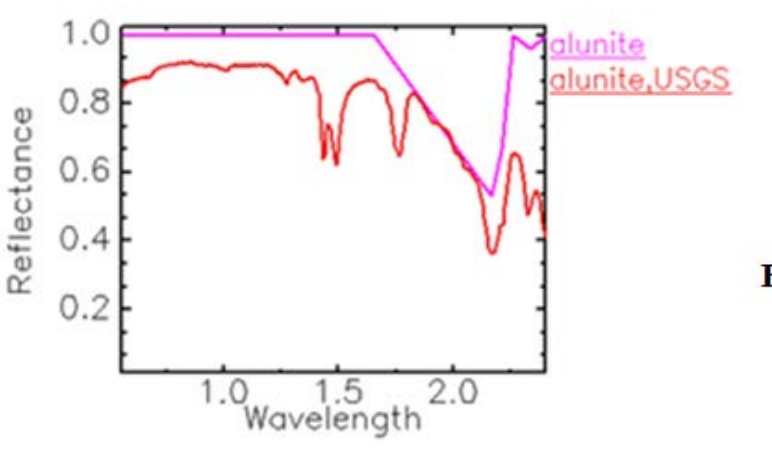

Figure 5. (A) Laboratory and field samples of mineral reflectance spectra in the study area; (B) Magnetite spectra from field sample and USGS; (C) Kaolinite spectra from field sample and USGS; (D) Dolomite spectra from field sample and USGS; (E) a-alunite (ammonioalunite) spectra from field sample and USGS; (F) alunite spectra from field sample and from USGS.

Based on the discriminated areas, there is no evidence of alteration minerals around parts of north-east and south-east. It may be because alteration is weak and small around these areas. Most areas with existing wells and under active exploration are in correspondence with the mapped induced alterations. Therefore, by applying a correct threshold to supervised classification techniques such as SAM, successful identification of hydrocarbon potential areas can be achieved.

\subsubsection{Lineament Density Map}

Lineament analysis provided important information on subsurface fractures and cracks. Lineaments were successfully mapped in the study area as shown in Figure 6. The lineament density was classified in a range of high to low. The highest lineament density area is found in the southern part of the study area whereas the lowest is recorded in parts of eastern side of the study area as shown in Figure 7. The areas of higher lineament density are basically mountainous with secondary porosity like joints and fractures which are the basis of the lineaments.

In general, lineaments are associated with highly weathered/fractured zones thus considered to be potential routes for leaking hydrocarbons. The mapped lineaments are likely influenced by subsurface geological structures and conditions such as faulting, resulting to high concentration in areas of high dense rocks.

The rose diagram of the lineaments indicated two dominant trends in north-east and south-west and one minor trend in east-west as shown in (Figure 8.) 


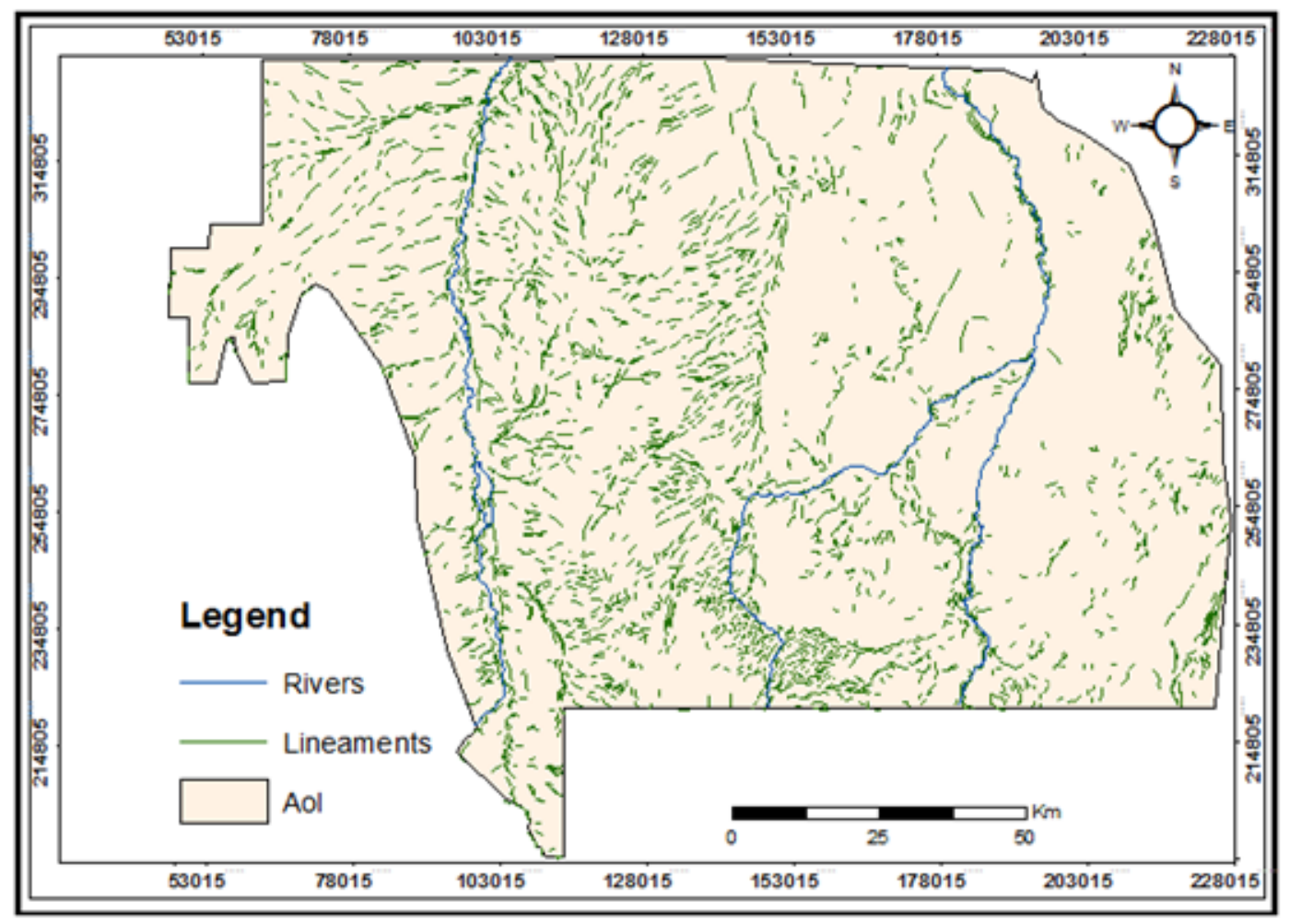

Figure 6. Derived Lineament

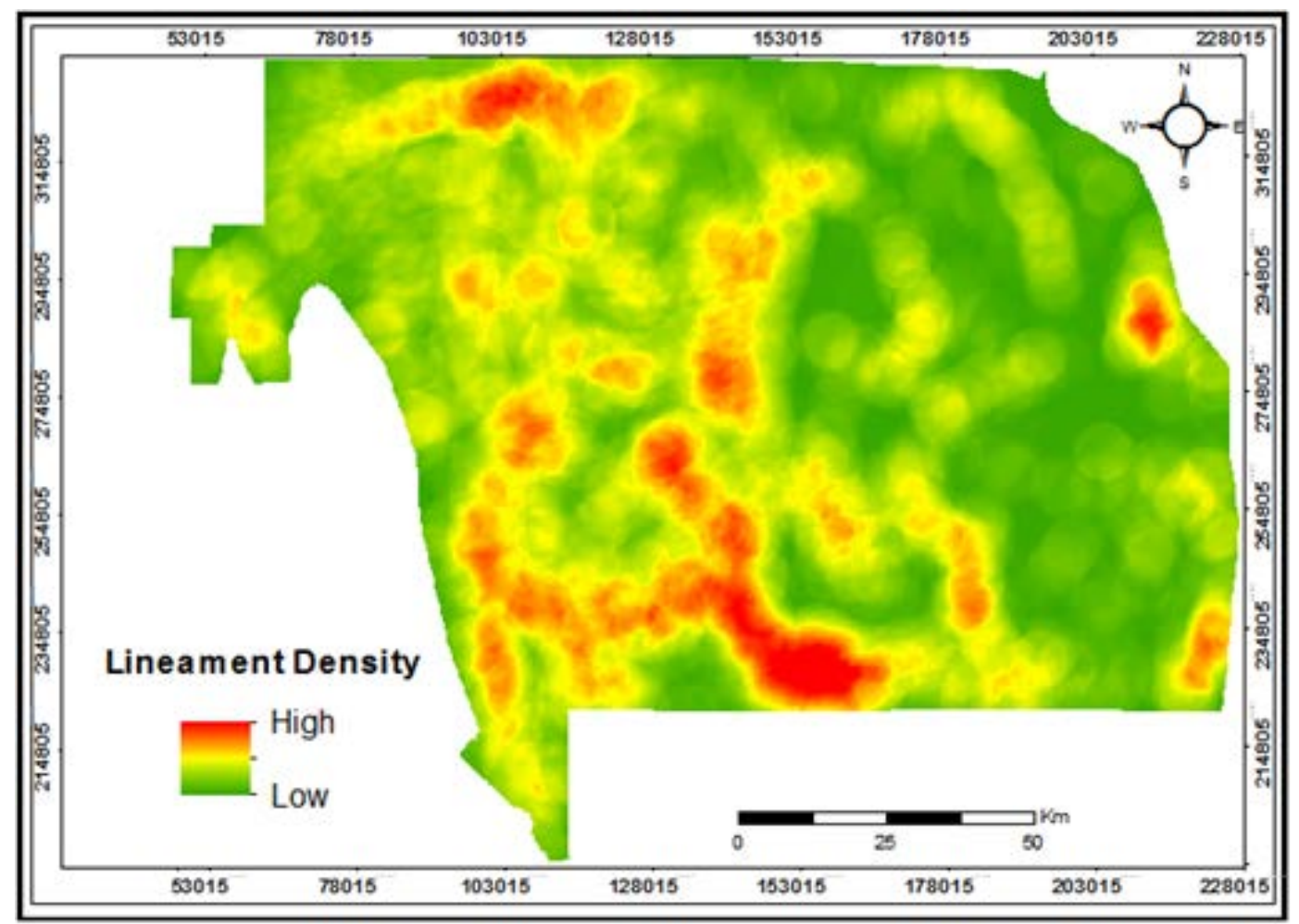

Figure 7. Map showing lineament density 


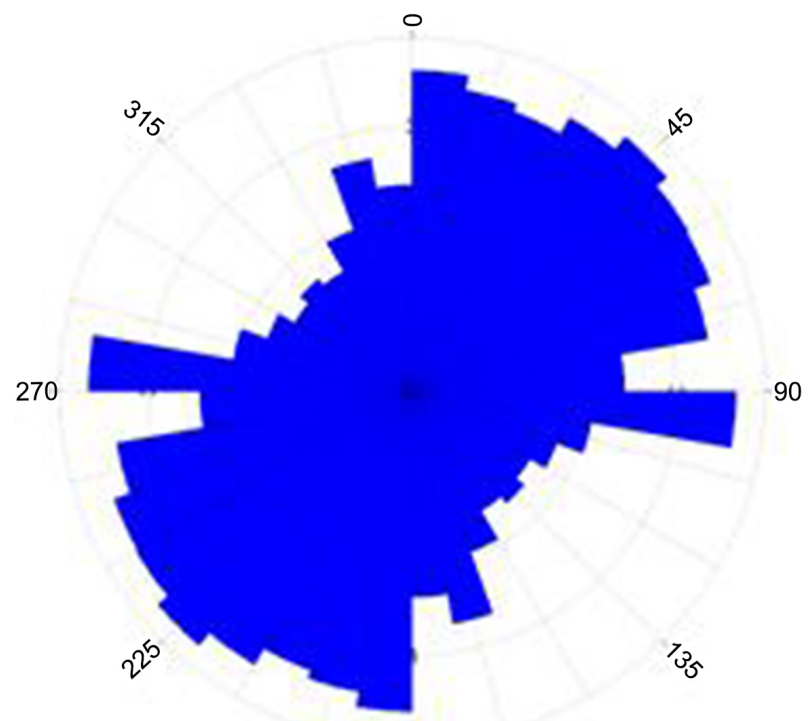

Figure 8. Lineament Trends

\subsubsection{Gravity Anomaly Maps}

Residual gravity anomaly provided a basis for understanding the near-subsurface structures and materials, and also understanding of hydrocarbon accumulation within sub-basins. Because hydrocarbons are restricted to the sediments, they are always reflected by signatures of gravity lows. Several gravity lows were mapped with the largest being at the centre and southern part of the study area. These areas clearly show basin deepening, acting as collection centres for sediments that favour hydrocarbon formation. Gravity lows in the study area for residual anomaly are as shown in Figure 9 and varies from -189.345 to $51.9474 \mathrm{mGal}$. At least 20 gravity lows were mapped with the lowest registering $-189.345 \mathrm{mGal}$, representing the deepest part of the basin at the southern part of the study area. Several other gravity lows scattered in the study area mapped are in the range of between -56.466 to -9.108 representing areas of depression. All depressions are separated from each other by relatively high dense rocks/uplift represented by gravity highs. All mapped depressions are considered as potential for hydrocarbon formation and accumulation.

Deeply buried structures were emphasized by regional gravity anomaly as shown in Figure 10. The largest depression was mapped at the center of the study area towards south. This depression is consistent with the depressions mapped from residual gravity anomaly. Three other similar depressions were mapped on south-west, west and north-western parts of the study area. The existence of a large basin in the study area as represented by gravity lows demonstrates a possibility of high sediment accumulation, translating to hydrocarbon accumulation.

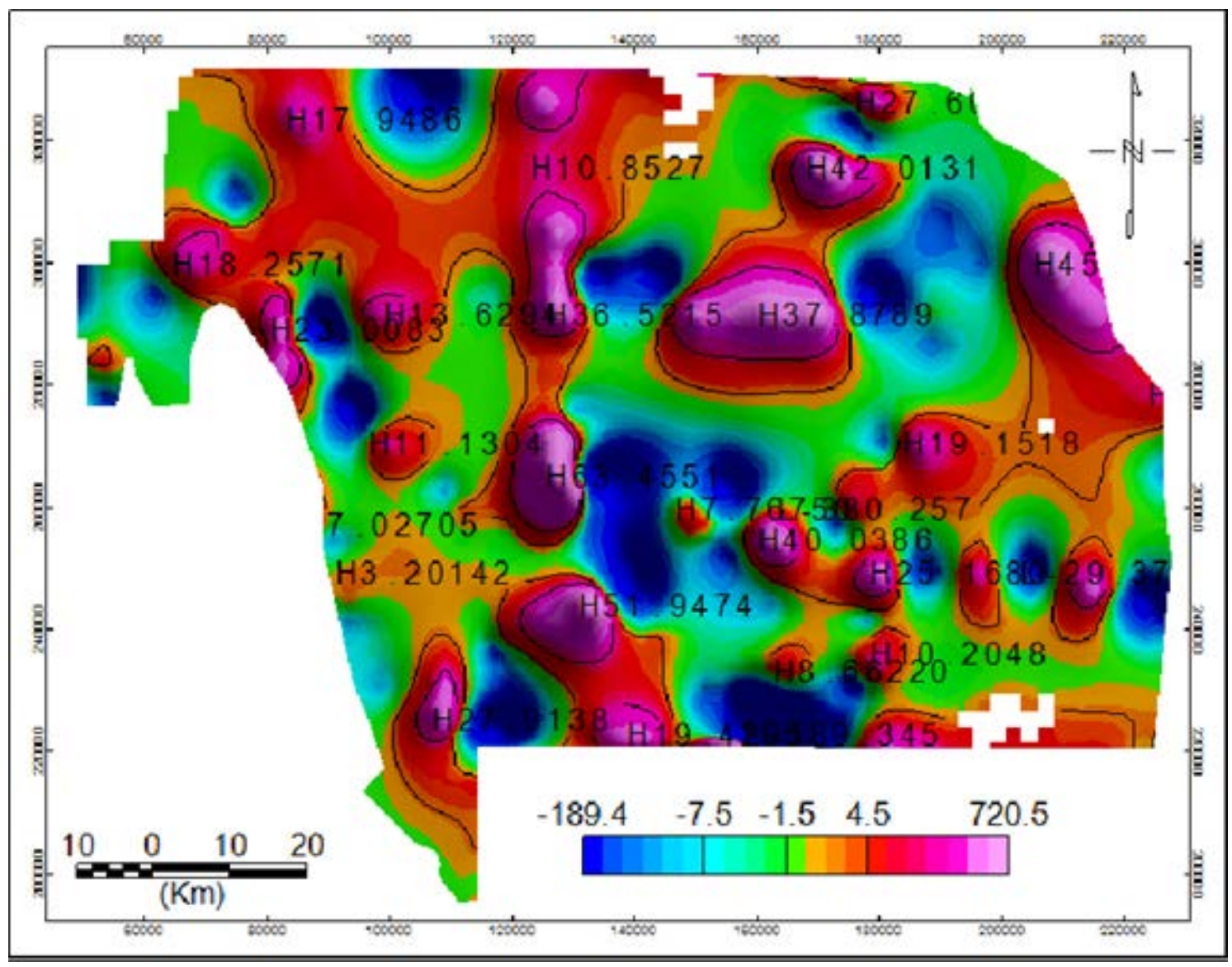

Figure 9. Residual gravity anomaly maps showing gravity lows and highs derived from Complete Bouguer Anomaly (CBA) data 


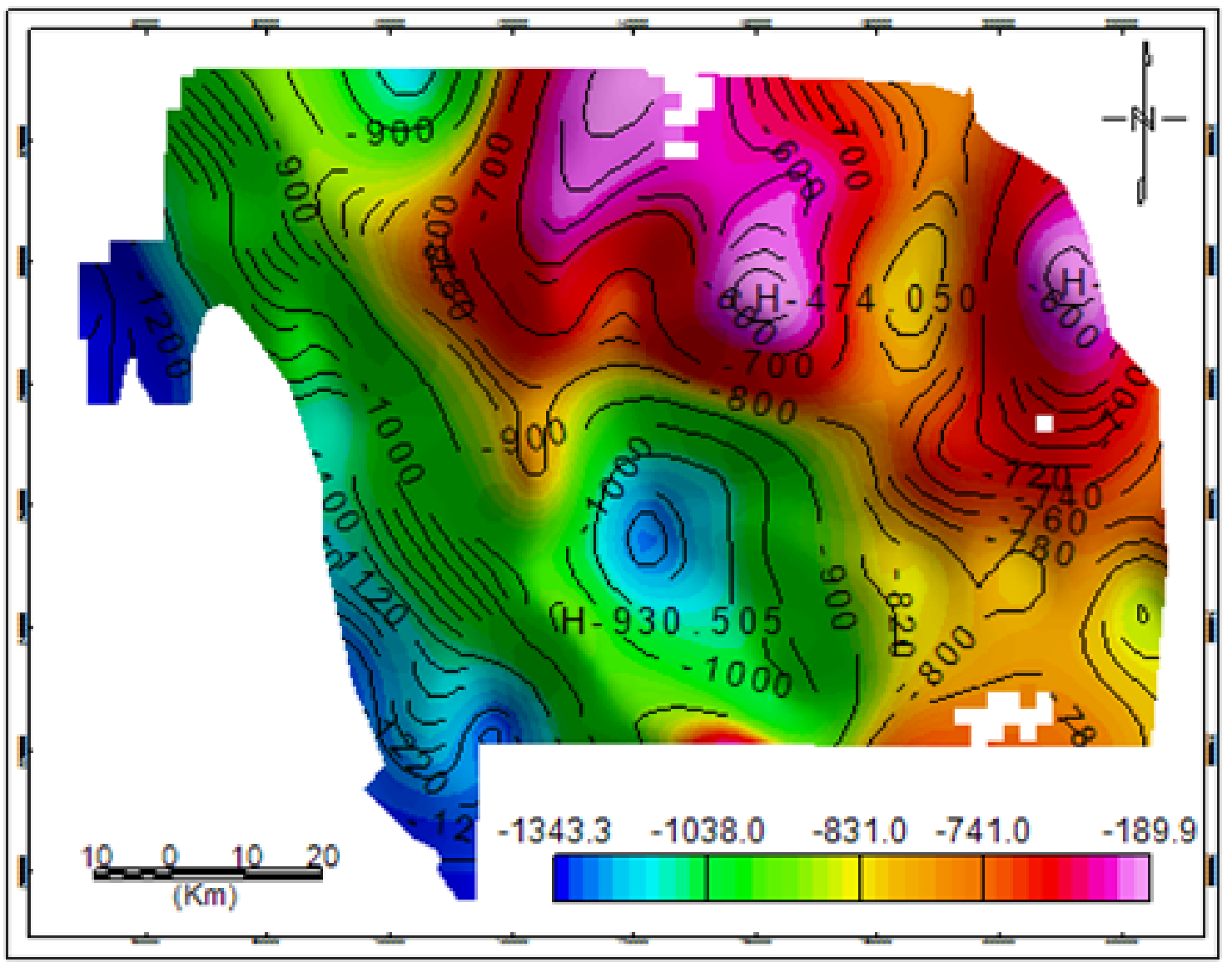

Figure 10. Regional gravity anomaly maps showing gravity lows and highs derived from Complete Bouguer Anomaly (CBA) data

Radially averaged power spectrum and depth estimates for density interfaces of the Forward (FFT) image calculated and plotted showed densities contributing to long and short wavelengths as shown in Figure 11. High values of natural log and depth represent deep sources while low values of natural log and depth represent shallow sources.

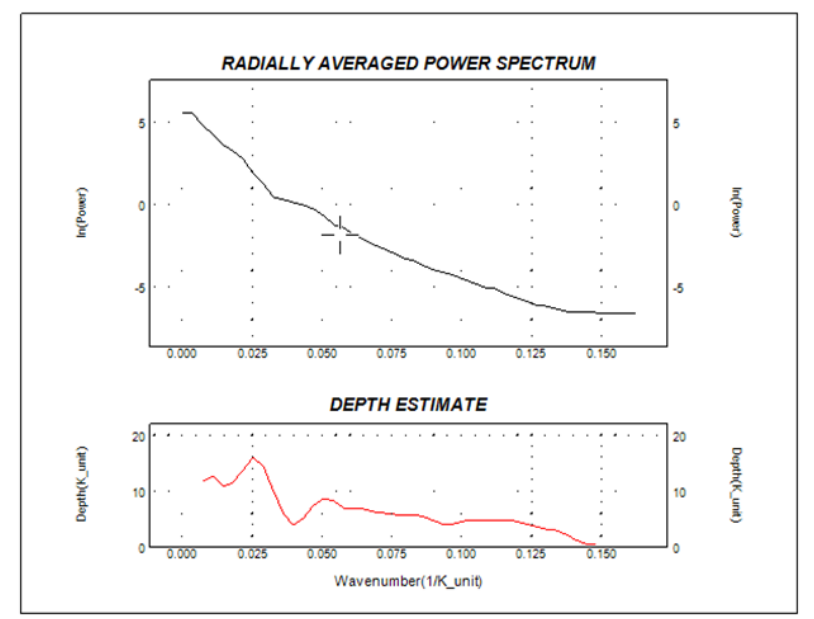

Figure 11. Graph representing the natural logarithm of radially averaged power density spectrum and depth in kilometers for depth estimate versus radial wavenumber for complete boguer anomaly map.

\subsubsection{Proximity to Fault Map}

Proximity to fault map was generated to illustrate the influence of fault on hydrocarbon accumulation as shown in Figure 12.

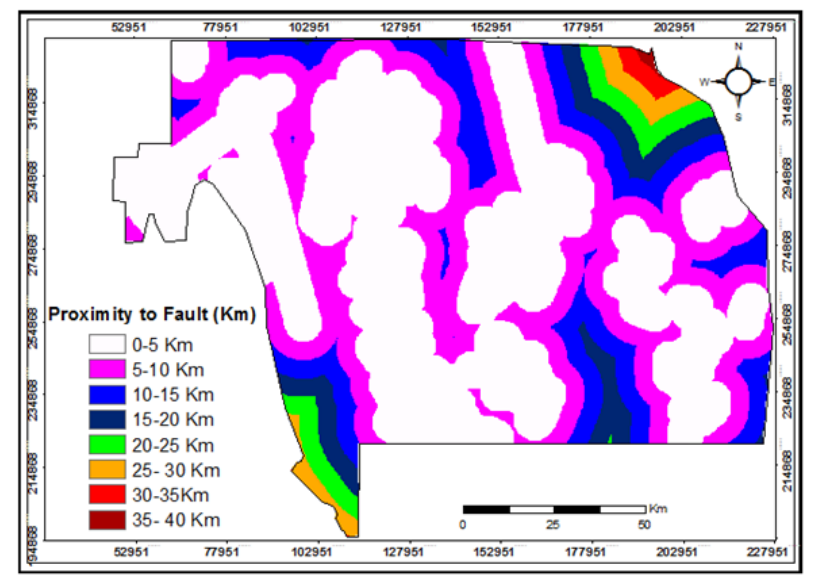

Figure 12. Proximity to fault map showing distance variation in kilometres at $5 \mathrm{~km}$ interval

Hydrocarbon formation is always controlled by fault location which contributes to hydrocarbon formation within a basin. Faults are also excellent pathways for leaking hydrocarbon. Most of the current wells in the study 
area are within a radius of $10 \mathrm{~km}$ from the fault lines. This shows that, hydrocarbon concentration are greatest near faults. Also, based on the $5 \mathrm{~km}$ radius proximity, new promising areas for example south eastern part of the study area were identified.

The faults in the study area consist of two major trends in northwest-southeast and northeast-southwest as shown in Figure 13.

\section{Lithology Map}

The study area comprises of nine lithological units as shown in Figure 14, namely pyroclastic unconsolidated, intermediate igneous, igneous rock, fluvial, eolian unconsolidated rock, classic sediments, basic igneous, acid metamorphic and acid igneous. Each lithology unit present were analyzed and evaluated based on its influence on hydrocarbon accumulation.

Understanding of rock characteristics in terms of compactness, weathering status, joints and fractures is always important in lithology. Eolian unconsolidated and classic sediments occupied the largest parts of the study area. The two rock units are formed as a result of sediment accumulation and therefore considered as sources and host of hydrocarbon as demonstrated by the location of current wells. Igneous rocks are hardly eroded and difficult to penetrate, therefore do not favor sediment accumulation hence considered as poor petroleum potential areas.

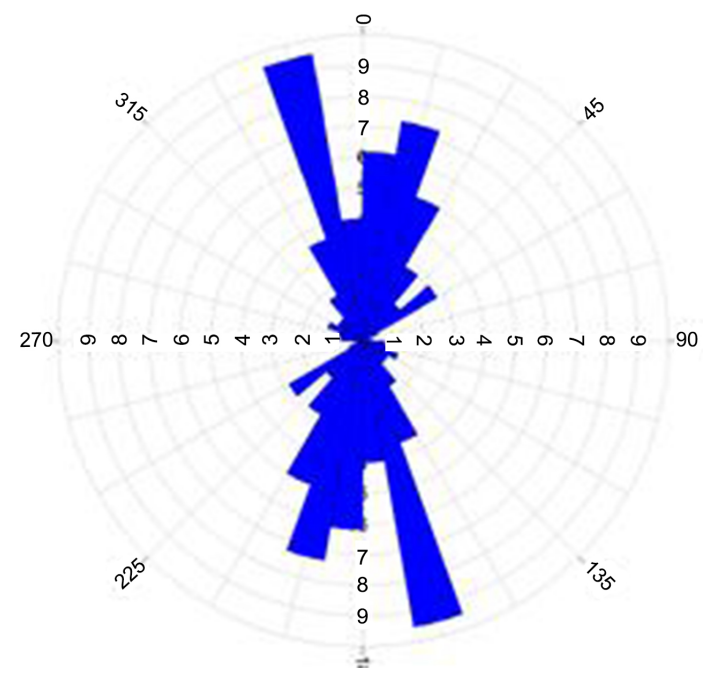

Figure 13. Major Fault trends in the study area

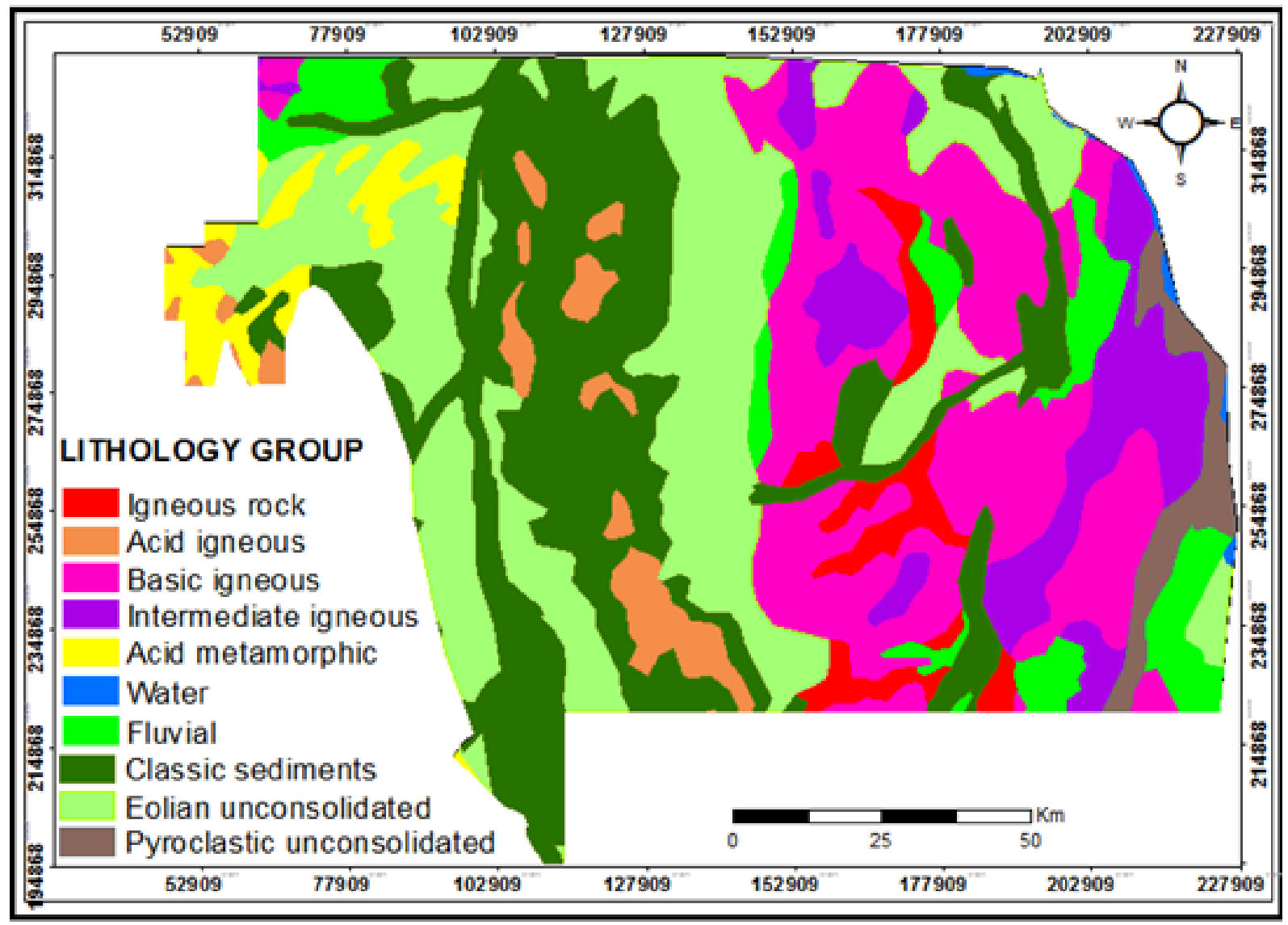

Figure 14. Lithology map showing various rock units in the study area 


\section{Discussion}

The favorability map of the petroleum potential area was generated based on the posterior probability as derived from PNN. 20 known wells locations were used to train the model with a corresponding 20 non-well locations. The weight of contribution of each input predictor to the final potential map was calculated as shown Table 1. According to the results, residual gravity anomaly was the highest contributor with $28 \%$, followed by regional gravity anomaly with $26 \%$ and then alterations with $14 \%$. The lowest percentage of contribution was recorded by lineaments at $10 \%$. Based on the percentage of contribution, the best predictors for petroleum in the study area were gravity anomalies and alteration. Lineament density recorded the least percentage weight among all the predictors. This poor association between lineament density and petroleum potential could have resulted from the fact that most lineaments were recorded in areas with high density rocks. Also, most lineaments in the study areas could have resulted from erosion caused by fast flowing water from the mountain areas.

After successful classification, the PNN classification overall measure was recorded to help in evaluating the network ability to classify correctly the input features. The overall measures were as follows: minimum fit to class was 0.0157; maximum fit to class was 1.0000; Mean Square Error (MSE) was 0.0873. These results suggest that the PNN model could be used to estimate the presence or absence of hydrocarbon occurrence. The final petroleum potential map was generated as shown in Figure 15 Probability of petroleum occurrence in the study area ranged between 0.0329 and 1 , with 1 representing highest probability and 0.0329 the lowest probable area.

Table 1. Percentage weight of contribution for each predictor

\begin{tabular}{llll}
\hline Predictors & Area in Square Km $\left(\mathbf{K M}^{2}\right)$ & Standard Weight & Percentage Weight \\
\hline Residual Gravity Map & $3,402.15$ & 0.941 & $24.54 \%$ \\
Regional Gravity Map & $12,144.63$ & 0.87 & $22.69 \%$ \\
Alteration Map & $16,141.75$ & 0.678 & $17.68 \%$ \\
Lithology Map & $14,628.44$ & 0.552 & $14.40 \%$ \\
Fault Map & $12,592.06$ & 0.47 & $12.26 \%$ \\
Lineament Density Map & $11,922.75$ & 0.323 & $8.42 \%$ \\
\hline
\end{tabular}

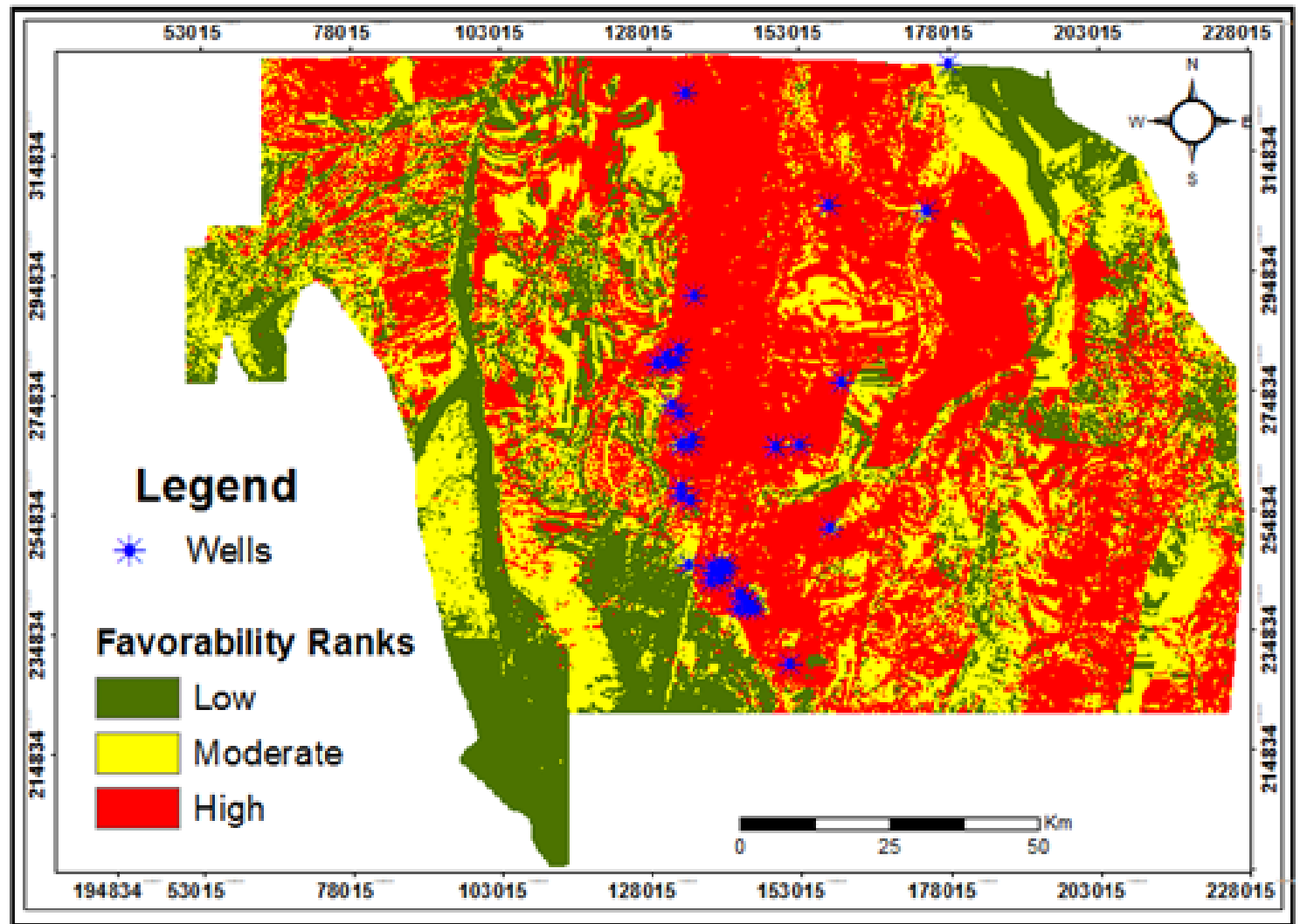

Figure 15. Petroleum potential map 
The training and validation data were also plotted as shown in Figure 16 below.

\subsection{Analysis and Interpretation}

The output from the PNN model showed that out of 20 training sites for well location used to model the predictors, 17 wells were within high potential areas, 2 in moderate and 1 in low potential areas as shown in (Table 2) below. This shows that most of the well sites are within high potential areas. The training data was based on the available well data; hence some areas within the study were not sufficiently covered. For validation points, 8 well sites were within high favorable. Only one well was mapped in moderate areas. This shows that the generated potential map was in good agreement with the existing wells.

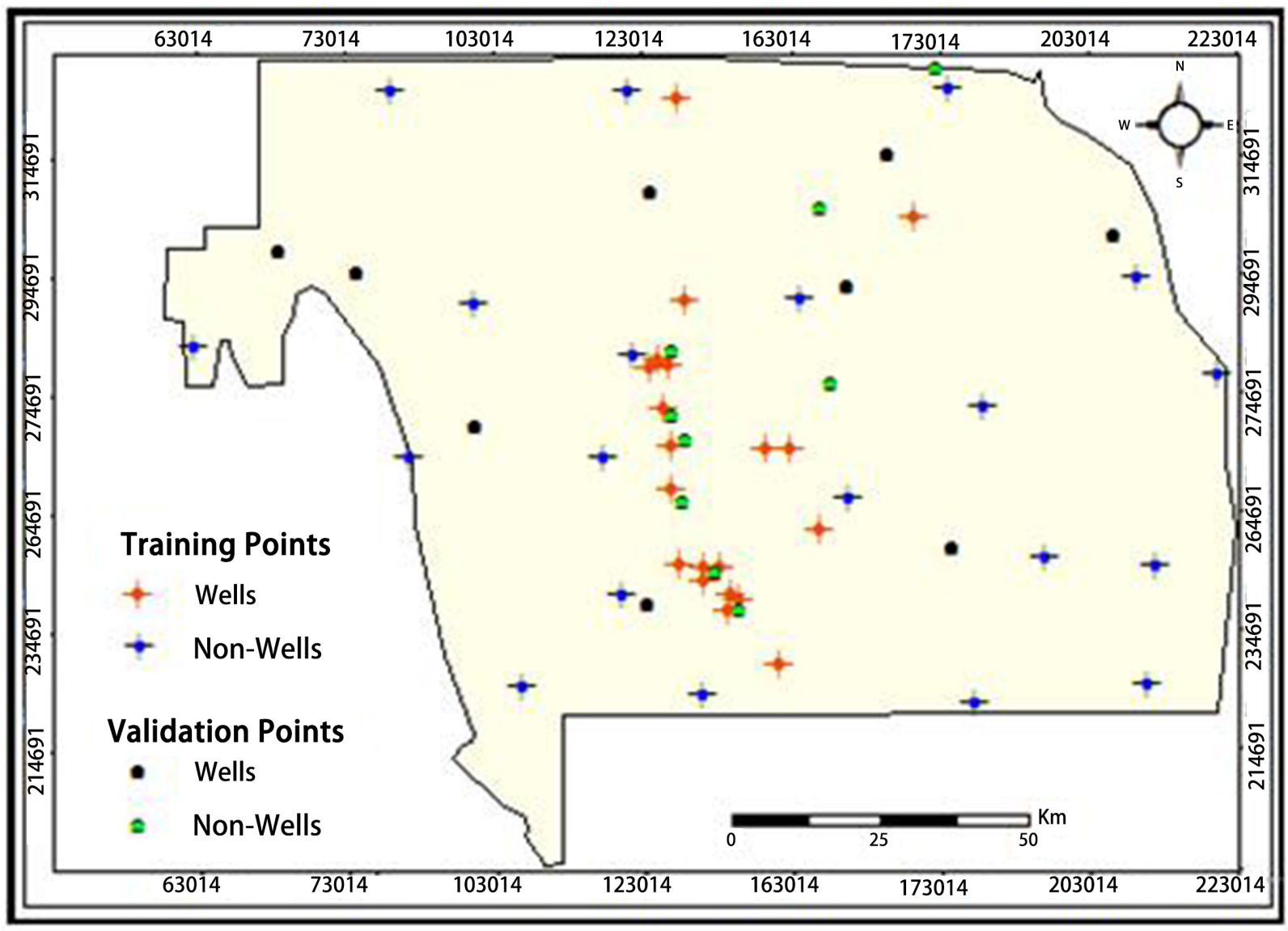

Figure 16. Map showing training and validation points for both wells and non-wells in the study area

Table 2. Summary of results showing number of training and validation points in each favorability

Favorability Area in km2 Study area Percentage

\begin{tabular}{lllcccc} 
& & & Wells & Non Wells & Wells & Non Wells \\
\hline High & 8994.41 & $55.90 \%$ & 17 & 2 & 8 & 0 \\
Moderate & 4675.35 & $29.10 \%$ & 2 & 6 & 1 & 3 \\
low & 2409.75 & $15 \%$ & 1 & 12 & 0 & 6 \\
\hline
\end{tabular}


The final potential map indicates that out of $16,079.51$ $\mathrm{km}^{2}$, the high potential zone covered an area of $8,994.41$ $\mathrm{Km}^{2}$ equivalents to $55.9 \%$, moderate potential $4,675.35$ $\mathrm{Km}^{2}$, equivalent to $29.1 \%$ and low potential $2,409.75 \mathrm{Km}^{2}$, equivalent to $15 \%$. The high potential areas were in consistent with the known well sites in the study area. The north-south region of study area has experienced many exploration activities and as shown in the final map, it has the highest potential.

New potential areas were also mapped especially in the south-eastern and north-western parts of the study area; this is because the study area is still under exploration. The new zones of high potentials can be interpreted as very important areas of focus for future petroleum exploration. The gravity lows, alterations and low-density rocks demonstrated by the predictor maps in these areas indicate the presence of hydrocarbon accumulation.

The integration of various predictor maps in ANN for the study area has demonstrated that there is a strong correlation between the existing well sites or exploration areas and high potential zones. The predictor maps also showed some correlation with the well sites. PNN is therefore considered to be important in mapping the petroleum potential areas in the study area.

\subsection{Validation}

The petroleum potential area result was validated using known well location data. The validation was done by comparing the probability values of petroleum potential based on the training results with the actual petroleum potential. The results of comparison are shown in Figure 17 as receiver operating characteristics (ROC) curve. The curve demonstrates how fine the input predictor maps and the model mapped the petroleum potential areas within the study area, hence giving a provision of spatial association between the training results and validation results.

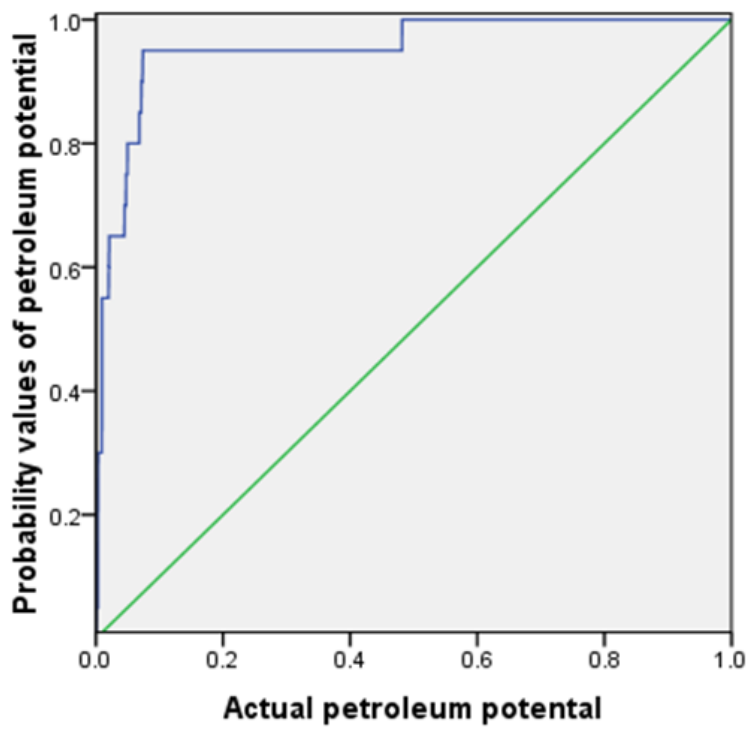

Figure 17. Receiver Operating Characteristic Curve showing efficiency of classification
Table 3. Area under the Curve (AUC)

\begin{tabular}{|c|c|c|c|c|}
\hline \multirow{2}{*}{ Area } & \multirow{2}{*}{$\begin{array}{c}\text { Std. } \\
\text { Error }^{\mathrm{a}}\end{array}$} & \multirow{2}{*}{$\begin{array}{c}\text { Asymptotic } \\
\text { Sig. }\end{array}$} & \multicolumn{2}{|c|}{$\begin{array}{r}\text { Asymptotic 95\% Confidence } \\
\text { Interval }\end{array}$} \\
\cline { 4 - 5 } & & Lower Bound & Upper Bound \\
\hline .953 & .023 & .000 & .908 & .998 \\
\hline
\end{tabular}

The test result variable(s): PNN has at least one tie between the positive actual state group and the negative actual state group. Statistics may be biased.

The area under the curve (AUC) was calculated as a fraction of the total area of the ROC curve. The model performance was varied from 0 to 1.0. An AUC model score of 1 is considered perfect while an AUC score of 0.5 indicates that the prediction is worth less than a chance [20]. The calculated AUC for the model was 0.953 which is an excellent discrimination. This clearly shows that the constructed ANN model could be used to map petroleum potential areas within the entire study area

\section{Conclusions}

This is the first study in Kenya for predicting the petroleum potential areas based on data integration in ANN. The final petroleum potential based on the input predictor datasets for high potential areas in the study area has indicated a match with the existing petroleum zones and wells. The majority of the study area is also covered by high potential zone. This is also in accordance with the existing exploration activities in the study area.

Based on the findings, this technique can be applied prior to any petroleum exploration to limit the size of the study area and to identify areas of interest within an exploration area. The final map will also provide spatial information on petroleum resources. This information is essential in allowing planning authorities to visualize the extent and spatial distribution of petroleum resources and to relate them to other forms of land use or to other factors (such as transport and environmental information).

Integration of gravity data with geology and satellite data in a GIS framework proved that petroleum controlling parameters can be mapped and used to predict possible hydrocarbon areas.

The importance of this approach in delineating potential zones for petroleum through data integration was also achieved. The result and technique can be transferred to other areas and used as a guideline for future studies.

This research was based on ASTER (Remote sensing data), gravity data and geological data. For future studies, we recommend use of RADAR satellite images to extract lineaments, hyperspectral images for alteration and magnetic data.

\section{REFERENCES}

[1] F. Frassy et al., "SATELLITE REMOTE SENSING FOR 
HYDROCARBON EXPLORATION IN NEW VENTURE AREAS Laboratory of Remote Sensing ( L @ RS ), Politecnico di Milano - Department of Architecture , Built Environment and Construction Engineering ( $\mathrm{ABC}$ ), Via Ponzio 31 , 20133 Milano ,” pp. 2884-2887, 2015.

[2] G. F. Bonham-Carter, "Geographic Information Systems for Geoscientists: Modelling with GIS,” Pergamon Press. Oxford, p. 398, 1994.

[3] M. S. Alshayef, A. Mohammed, B. Mohammed, and M. S. Alshayef, "Integration Based GIS Weighted Linear Combination ( WLC ) model for Delineation Hydrocarbon Potential ... Integration Based GIS Weighted Linear Combination ( WLC ) model for Delineation Hydrocarbon Potential Zones in inAyad Ayad Area ( Yemen ) Using Analy,” SSRG Int. J. Geo informatics Geol. Sci., vol. 4, no. July, pp. 0-10, 2017.

[4] N. W. Anatolia, "Bulletin of the Mineral Research and Exploration Figure,” pp. 1-17, 2013.

[5] A. A. Madani, "Knowledge-driven GIS modeling technique for gold exploration, Bulghah gold mine area, Saudi Arabia," Egypt. J. Remote Sens. Sp. Sci., vol. 14, no. 2, pp. 91-97, 2011.

[6] A. Mohammed, B. Mohammed, A. Javed, and M. S. Alshayef, "Spatial Data Modeling Based MCE Fuzzy Logic for Petroleum Exploration in Part of Say ' un-Masilah Basin of Yemen,” Am. J. Remote Sens., vol. 5, no. 1, pp. 1-9, 2017.

[7] M. Abedi, A. Gholami, and G. H. Norouzi, “A stable downward continuation of airborne magnetic data: A case study for mineral prospectivity mapping in Central Iran,” Comput. Geosci., vol. 52, no. November, pp. 269-280, 2013.

[8] E. J. M. Carranza, F. J. A. van Ruitenbeek, C. Hecker, M. van der Meijde, and F. D. van der Meer, "Knowledge-guided data-driven evidential belief modeling of mineral prospectivity in Cabo de Gata, SE Spain,” Int. J. Appl. Earth Obs. Geoinf., vol. 10, no. 3, pp. 374-387, 2008.

[9] G. F. Bonham-Carter, F. P. Agterberg, and D. F. Wright, "Integration of Geological Data Sets for Gold Exploration in Nova Scotia,” Photogramm. Engeneering Remote Sens., vol. 54, no. c, pp. 1585-1592, 1988.

[10] C. Kwang, E. M. Osei jnr, and A. A. Duker, “Application of Remote Sensing and Geographic Information Systems for Gold Potential Mapping in Birim North District of Eastern Region of Ghana -Gold Potential Mapping Using GIS and Remote Sensing,” Int. J. Remote Sens. Appl., vol. 4, no. 1, p. 48, 2014.

[11] E. J. M. Carranza, M. Hale, A. Porwal, E. J. M. Carranza, and M. Hale, "Artificial Neural Networks for Mineral-Potential Mapping: A Case Study from Aravalli Province, Western India Artificial Neural Networks for Mineral-Potential Mapping: A Case Study from Aravalli Province, Western India,” Nat. Resour. Res., vol. 12, no. May 2014, pp. 154-171, 2003.

[12] H. Haroni and A. Lavafan, "Integrated Analysis of ASTER and Landsat ETM Data to Map Exploration Targets in the Muteh Gold-Mining Area, IRAN,” 5th Int. Symp. Spat. Data Qual. ..., 2007.
[13] A. Ghulam, "Mineral Exploration and Alteration Zone Mapping in Eastern,” ASPRS 2010 Annu. Conf., 2010.

[14] A. M. Eldosouky, M. Abdelkareem, and S. O. Elkhateeb, "Integration of remote sensing and aeromagnetic data for mapping structural features and hydrothermal alteration zones in Wadi Allaqi area, South Eastern Desert of Egypt,” J. African Earth Sci., vol. 130, pp. 28-37, 2017.

[15] K. C. Das, V. S. B. Sarma, and M. Ayyadurai, “Gondwana Sediments: A Promising Hydrocarbon Exploration Target in Assam Shelf,” 5th Conf. Expo. Pet. Geophys., vol. 1, pp. 468-472, 2004.

[16] S. M. Saad Khana, b, Said Rahmanc, Mateeul Haqc, "Hyperspectral Remote Sensing for Detection of Natural Hydrocarbon Seeps Saad,” Asian J. Multidiscip. Stud., vol. 8819, no. 7, pp. 95-101, 2016.

[17] D. Schumacher, "Hydrocarbon-Induced Alteration of Soils and,” AAPG Mem., vol. 66, no. March, pp. 71-89, 1996.

[18] P. Shi, B. Fu, Y. Ninomiya, J. Sun, and Y. Li, "Multispectral remote sensing mapping for hydrocarbon seepage-induced lithologic anomalies in the Kuqa foreland basin, south Tian Shan,” J. Asian Earth Sci., vol. 46, no. June 2016, pp. 70-77, 2012.

[19] F. van der Meer, P. van Dijk, H. van der Werff, and H. Yang, "Remote sensing and petroleum seepage: A review and case study,” Terra Nov., vol. 14, no. 1, pp. 1-17, 2002.

[20] S. Salati, F. van Ruitenbeek, F. van der Meer, and B. Naimi, "Detection of alteration induced by onshore gas seeps from ASTER and worldview-2 Data,” Remote Sens., vol. 6, no. 4, pp. 3188-3209, 2014.

[21] C. A. Torres, "Mineral Exploration Using GIS and Processed Aster Images,” vol. 6513, no. Spring, 2007.

[22] K. Aleks and S. Oliver, “ASTER Mineral Index Processing Manual,” Remote Sens. Appl. Geosci. Aust., no. October 2004, 2004.

[23] “ASTER Data Analysis Applied to Mineral Resource Exploration and Geological Mapping ASTER YAJIMA, Taro.”

[24] M. Hosseinjani Zadeh and M. Honarmand, "A remote sensing-based discrimination of high- and low-potential mineralization for porphyry copper deposits; a case study from Dehaj-Sarduiyeh copper belt, SE Iran,” Eur. J. Remote Sens., vol. 50, no. 1, pp. 332-342, 2017.

[25] F. D. van der Meer et al., "Multi- and hyperspectral geologic remote sensing: A review,” Int. J. Appl. Earth Obs. Geoinf., vol. 14, no. 1, pp. 112-128, 2012.

[26] A. Petrovic, S. D. Khan, and H. S. Chafetz, "Remote detection and geochemical studies for finding hydrocarbon-induced alterations in Lisbon Valley, Utah," Mar. Pet. Geol., vol. 25, no. 8, pp. 696-705, 2008.

[27] G. T. Hunt, SPECTRAL SIGNATURES OF PARTICULATE MINERALS IN THE VISIBLE AND NEAR INFRARED. 1977.

[28] T. Zhang et al., "Integrating data of ASTER and Landsat-8 OLI (AO) for hydrothermal alteration mineral mapping in duolong porphyry cu-au deposit, Tibetan Plateau, China," 
Remote Sens., vol. 8, no. 11, 2016.

[29] J. S. Lore, P. Eichhubl, and A. Aydin, "Alteration and fracturing of siliceous mudstone during in situ combustion, Orcutt field, California,” J. Pet. Sci. Eng., vol. 36, no. 3-4, pp. 169-182, 2002.

[30] T. Lammoglia, C. R. S. Filho, and R. Almeida-Filho, "Characterization of Hydrocarbon Microseepages in the Tucano Basin, (Brazil) Through Hyperspectral Classification and Neural Network Analysis of Advanced Spaceborne Thermal Emission and Reflection Radiometer (Aster ) Data,” Int. Arch. Photogramm. Remote Sens. Spat. Inf. Sci., vol. XXXVII, no. B8, pp. 1195-1200, 2008.

[31] A. A. Khamies and M. M. El-Tarras, "Surface and subsurface structures of Kalabsha area, southern Egypt, from remote sensing, aeromagnetic and gravity data," Egypt. J. Remote Sens. Sp. Sci., vol. 13, no. 1, pp. 43-52, 2010.

[32] S. M. G. N. Bahram Habibnia, "Lineaments Analysis of Tabnak Field Using,” J. Tethys, vol. 1, no. November, pp. 56-67, 2015.

[33] S. D. Khan and S. Jacobson, "Remote sensing and geochemistry for detecting hydrocarbon microseepages," Bull. Geol. Soc. Am., vol. 120, no. 1-2, pp. 96-105, 2008.

[34] B. K. Rop, “Hydrocarbon Prospects under Lake Turkana Basin, NW- Kenya: Based on Geophysical and Geochemical Data Investigations,” Res. J. Eng. Technol., vol. 1, no. 2, pp. 41-56, 2015.

[35] A. Mohammed, K. Palanivel, C. J. Kumanan, and S. M. Ramasamy, "Significance of Surface Lineaments for Gas and Oil Exploration in Part of Sabatayn Basin-Yemen,” J. Geogr. Geol., vol. 2, no. 1, pp. 119-128, 2010.

[36] J. I. Boyce and W. A. Morris, "Basement-controlled faulting of Paleozoic strata in southern Ontario, Canada: new evidence from ...,” Tectonophysics, vol. 353, pp. 151-171, 2002.

[37] F. Report, U. Contract, R. Engineering, and P. Alto, “National Petroleum Technology Office.” vol. 5, 1999.

[38] M. Khashei and M. Bijari, “An artificial neural network (p, d, q) model for timeseries forecasting,” Expert Syst. Appl., vol. 37, no. 1, pp. 479-489, 2010.
[39] J. F. Mas and J. J. Flores, "The application of artificial neural networks to the analysis of remotely sensed data," Int. J. Remote Sens., vol. 29, no. December, pp. 617-663, 2017.

[40] A. Tessema, "Mineral Systems Analysis and Artificial Neural Network Modeling of Chromite Prospectivity in the Western Limb of the Bushveld Complex, South Africa," Nat. Resour. Res., vol. 26, no. 4, pp. 465-488, 2017.

[41] M. Hajmeer and I. Basheer, “A probabilistic neural network approach for modeling and classification of bacterial growth/no-growth data,” J. Microbiol. Methods, vol. 51, no. 2, pp. 217-226, 2002.

[42] E. M. Page, "Use of a Neural Network to Integrate Geoscience Information in the Classification of Mineral Deposits and Occurrences,” Integr. Explor. Inf. Manag., pp. 127-134, 1997.

[43] K. Z. Mao, K. C. Tan, and W. Ser, "Probabilistic neural-network structure determination for pattern classification,” IEEE Trans. Neural Networks, vol. 11, no. 4 pp. 1009-1016, 2000.

[44] D. A. Singer and R. Kouda, "Classification of mineral deposits into types using mineralogy with a probabilistic neural network Classification of Mineral Deposits into Types Using Mineralogy with a Probabilistic Neural Network,” Nonrenewable Resour., vol. 6, no. August 2014, pp. 26-32, 1997.

[45] B. K. Rop, "Petroleum potential of NW-Kenya Rift Basins : A synopsis of evidence and issues,” Pet. Geol. Forum, 2011.

[46] B. K. Rop, "Hydrocarbon characteristics of source rocks in Loperot-1 well, Northwest Kenya,” Kenya Geotherm. Conf., pp. 1-6, 2011.

[47] J. R. Harris et al., "Application of GIS Processing Techniques for Producing Mineral Prospectivity Maps - A Case Study: Mesothermal Au in the Swayze Greenstone Belt , Ontario , Canada,” Nat. Resour. Res., vol. 10, no. 2, pp. 91-124, 2001.

[48] J.Rigol-Sanchez, "Artificial neural networks as a tool for mineral potential mapping with with GIS,” Int. J. Remote Sens., vol. 24, pp. 1151-1156, 2003. 